\title{
A FAMÍLIA FRENTE AOS ASPECTOS DO CÂNCER
}

\author{
THE FAMILY FACING THE ASPECTS OF CANCER
}

\author{
Francisco Eudison da Silva Maia ${ }^{a^{*}}$, Francisca Erica da Silva Maia ${ }^{b * *}$ \\ aeudisonmaia@yahoo.com.br, bhericamaia@gmail.com \\ *Universidade Potiguar - Mossoró (RN), Brasil \\ **Universidade do Estado do Rio Grande do Norte - Mossoró (RN), Brasil
}

Data de recebimento: 06/01/2016

Data de aceite: 29/05/2016

\section{RESUMO}

A família tem significativa importância nos cuidados com o paciente carcinomatoso, atuando como alicerce e proporcionando conforto emocional, uma vez que age com solidariedade. O presente artigo objetiva construir uma referência teórica representativa das mudanças ocorridas no contexto familiar após o diagnóstico da doença. Trata-se de uma revisão integrativa da literatura, realizada por meio da Biblioteca Virtual em Saúde (BVS) nas bases de dados Scielo, Lilacs e Medline. A delimitação de período de publicação foi de 2000 até 2014 . A pesquisa foi realizada no período de abril a junho de 2015 . Os descritores foram: relaçôes familiares; neoplasias; morte. A literatura aponta que a harmonia familiar é abalada frente à perspectiva do câncer para com um dos seus membros. Com isso pode-se concluir que a família tem um papel fundamental no desenvolvimento da convicção do paciente de que o tratamento é eficaz, podendo se transformar em um aliado forte e poderoso nesse contexto.

Palavras-chave: Relaçôes familiares; neoplasias; diagnóstico; terapêutica.

\section{ABSTRACT}

The family has significant importance in the care of the patient with cancer, supporting him and providing emotional comfort. This article aims to build a representative theoretical framework of changes in the family context after the diagnosis. It is an integrative literature review, performed by Biblioteca Virtual em Saúde (BVS - "Virtual Health Library", in Portuguese) in Scielo, Lilacs and Medline databases. The delimitation of publication period was apart from 2000 to 2014. The survey was conducted from April to June of 2015. The descriptors for the research were: family relationships; neoplasms; death. The literature suggests that family harmony is shattered against the cancer perspective towards one of its members. Thus, we conclude that the family plays a key role in developing the patient's belief that the treatment is effective and can become a strong and powerful ally in this context.

Keywords: Family relations; neoplasms; diagnosis; therapeutics. 


\section{Introdução}

Compreende-se que desde o momento em que o indivíduo conjetura que pode ter câncer, deflagra-se em todo o sistema paciente-família um "alarme" que desencadeia uma série de reaçóes de aspectos pessimistas, de pânico, desespero e/ou caos. Essas reações se ampliam e se particularizam à medida que o diagnóstico do câncer é confirmado e se torna necessário assimilar, processar, elaborar e compreender o que está acontecendo, visando o enfrentamento necessário e adesão a um futuro tratamento ${ }^{1-3}$.

O diagnóstico do câncer e a possibilidade de sua confirmação estão intrinsecamente associados ao conceito de morte, pois mesmo continuando a viver, a marca da morte antecipada permanece para sempre nas pessoas que um dia se encontraram nessa situação. Existem muitas doenças fatais além do câncer, porém a impressão é que as outras doenças matam; o câncer destrói $i^{1,2}$.

A família que tem um dos seus membros carcinomatoso tem sido vista como um agente importante nos cuidados necessários a esse paciente. Propóe-se que a família também é um paciente de segundo escalão, devendo ser assistida cuidadosamente pela equipe de saúde. Assim, na ocorrência de mudanças na saúde de um dos seus integrantes, todos os demais são afetados, e a família como um todo passa por mudanças, pois o que afeta a saúde do indivíduo implicará também em resquícios à família ${ }^{1,3}$.

Com o intuito de apontar as perspectivas dos familiares em relação ao diagnóstico de câncer, o presente artigo irá analisar os mecanismos de enfrentamento utilizados e sua contribuição para o paciente acometido, objetivando conhecer melhor o processo de aceitação da família e apontar as mudanças ocorridas nesse meio.

\section{Metodologia}

Trata-se de uma revisão integrativa da literatura, método que consiste na síntese de um determinado assunto a partir da literatura já publicada, podendo identificar a necessidade para a realizaçáo de novos estudos como também reflexôes sobre melhorias na prática clínica ${ }^{4}$.

O levantamento bibliográfico foi feito por meio da Biblioteca Virtual de Saúde (BVS), nas bases de dados do Scielo (Scientific Electronic Library Online), Lilacs (Literatura Latino Americana e do Caribe em Ciências da Saúde) e Medline (Medical Literature Analysis and Retrieval System Online). Foram incluídos artigos completos, publicados nas línguas portuguesa e inglesa, realizados em seres humanos, sem distinção de gênero, idade ou classe social, com delimitaçáo de período de publicação de 2000 até 2014 . A pesquisa foi feita entre abril e junho de 2015.

Para construir o presente manuscrito, foram seguidas as seguintes etapas: o estabelecimento das questóes e objetivos da revisão integrativa; estabelecimento dos critérios de inclusão e exclusão de artigos; definição das informaçóes a serem extraídas dos artigos selecionados; análise dos resultados; discussão e apresentação dos resultados e, por último, a apresentação da revisão ${ }^{4}$.

$\mathrm{O}$ estudo foi desenvolvido com base na seguinte questão norteadora: como se comporta a família frente ao câncer?

Para delimitar os artigos, foram utilizados como critérios de inclusão: que investigasse ou relatasse os fatores representativos das mudanças ocorridas no contexto familiar após o diagnóstico da doença; estar disponível no idioma português e/ou inglês. Foram excluídos da amostra os editoriais e as cartas ao editor, pelo entendimento de que esse modelo de texto náo disponibiliza informações suficientes para alcançar os objetivos propostos.

Utilizou-se a seguinte estratégia de busca: cruzamento das palavras-chave "família", "neoplasia”, "diagnóstico" e "ajuda familiar", com os seguintes descritores: "relaçôes familiares"; "neoplasias"; "morte". Após a aplicação desses critérios, a busca resultou em um total de 473 publicações. Após a aplicação dos critérios de inclusão, foram eliminados 433. Nessa etapa, ficaram 40 artigos (conforme o Quadro 1). No momento exploratório, foram empreendidas leituras dos resumos desses artigos, evitando concomitantemente artigos duplicados e indexados em mais de uma base. Do montante dos 40, foram utilizados 36 , sendo 24 oriundos da base de dados do Scielo, 10 do Lilacs e 2 do Medline. Estes 36 foram utilizados para constituir o corpus da discussão devido a uma maior afinidade ao tema proposto.

\section{Resultados}

O Quadro 1 apresenta os artigos encontrados na BVS e seus respectivos periódicos e bases de dados. 
Quadro 1: Distribuição e quantidade dos artigos por periódicos, bases de dados com suas respectivas áreas temáticas e ano de publicação.

\begin{tabular}{|c|c|c|c|}
\hline Periódico/ BD & Qa & Ap & At \\
\hline Revista Latino-americana de Enfermagem /Scielo & 2 & $1996 / 2010$ & Enfermagem \\
\hline Revista Associação Medica Brasileira/Scielo & 6 & $1999 / 2001 / 2003 / 2004 / 2004 / 2007$ & Medicina \\
\hline Revista Brasileira Ginecologia e Obstetrícia/Scielo & 1 & 2002 & Medicina \\
\hline Arquivos Catarinenses de Medicina/Lilacs & 3 & 2003/2006/2006 & Medicina \\
\hline Jornal de Pediatria/Scielo & 2 & $2003 / 2003$ & Medicina \\
\hline $\begin{array}{l}\text { Arquivos de gastroenterologia e endoscopia digestiva/ } \\
\text { Scielo }\end{array}$ & 1 & 2005 & Medicina \\
\hline Jornal Brasileiro de Patologia Médica/Scielo & 3 & $2005 / 2005 / 2009$ & Medicina \\
\hline Revista Brasileira de Análises Clínicas/Lilacs & 11 & $\begin{array}{c}2005 / 2006 / 2006 / 2006 / 2008 / 2008 / 2 \\
009 / 2009 / 2010 / 2011 / 2011\end{array}$ & Farmácia \\
\hline Revista Panamericana de Infectologia/Scielo & 1 & 2005 & Medicina \\
\hline Acta Médico/Medline & 1 & 2006 & Medicina \\
\hline Revista Brasileira Saúde Materno Infantil/Scielo & 1 & 2007 & Medicina \\
\hline Revista Brasileira de Enfermagem/Scielo & 1 & 2007 & Enfermagem \\
\hline Revista Brasileira de Terapia Intensiva/Scielo & 1 & 2007 & Medicina \\
\hline J Obstet Gynaecol Res/Medline & 1 & 2007 & Medicina \\
\hline Ciência, Cuidado e Saúde/Lilacs & 1 & 2007 & Enfermagem \\
\hline Revista Paranaense de Medicina/Scielo & 1 & 2007 & Medicina \\
\hline Revista Brasileira de Clinica Médica/Lilacs & 1 & 2010 & Medicina \\
\hline Revista da Escola de Enfermagem da USP/Scielo & 1 & 2011 & Enfermagem \\
\hline Texto e Contexto/Scielo & 1 & 2011 & Enfermagem \\
\hline
\end{tabular}

Das 40 referências inclusas, todas são de caráter multidisciplinar. A forma como se deu a busca literária e sua ampliação ocorreu visando uma maior abrangência da discussão.

\section{Discussões}

\section{O câncer}

O termo "câncer" engloba um grupo de distúrbios aparentados que têm em comum o crescimento celular desenfreado em alguma parte do corpo, podendo formar um tumor ${ }^{3-5}$.

O surgimento do câncer se deve a mutaçóes nos genes de uma célula que a torna anormalmente proliferativa, a ponto de formar uma massa tumoral. Várias transformaçôes podem acorrer na mesma célula para que esta adquira o caráter de maligna ${ }^{5-8}$.
O câncer é uma patologia que se desenvolveu com a humanidade e ao longo do tempo esteve associada a fatores místicos, à doença inglória advinda de castigos dos deuses ou a impurezas ${ }^{9,10}$.

Ainda nesse contexto, as neoplasias também foram associadas a precárias condiçóes de higiene física e também a questôes morais, o que gerava para a pessoa doente uma série de constrangimentos sociais. As pessoas que se encontravam doentes passavam a ser consideradas como cidadãos que não seguiam os preceitos de responsabilidade social. $\mathrm{O}$ indivíduo acometido pelo câncer era considerado responsável pelo seu próprio sofrimento ${ }^{11-14}$.

O câncer esteve por muito tempo sendo correlacionado com a sífilis, cancro, lepra e tuberculose, por essas doenças serem relacionadas a comportamentos desvirtuosos frente aos impostos pela sociedade ${ }^{1,7,9}$. Recebeu também uma imagem de corrosão do corpo, interpretada como uma espécie de verme que deforma 
o organismo, exalando odores fétidos e infectantes no ambiente, colocando a pessoa doente diante de situaçôes e condiçóes desumanizantes. No entanto, esteve presente também a ideia de redenção, em que diante do castigo recebido, a pessoa poderia alcançar a glória, se existisse resignação diante da dor e do sofrimento. Assim, ao mesmo tempo que era relacionada a um castigo, simultaneamente também era tratada como um mal redentor ${ }^{15-18}$.

As concepçóes sobre essa patologia só passaram a ser relativizadas à medida que as causas externas e internas da doença passaram a ser estudadas ${ }^{8,11,19-21}$.

Os símbolos acrescentados ao câncer geralmente representavam uma série de situaçóes que provocavam efeitos desagradáveis, dependendo da maneira como os doentes percebem a sua própria condição e as percepçóes das outras pessoas ${ }^{10,22,23}$.

Atualmente o câncer já é considerado na maior parte do mundo industrializado como um tipo de doença popular e, se tratada antecipadamente, apresenta prognósticos bastante satisfatórios ${ }^{19,24}$.

\section{Os aspectos familiares}

A palavra "família" engloba diferentes significados: para alguns pode ser associada a um grupo de pessoas unidas pelas mesmas convicçóes ou interesses, podendo estar intimamente correlacionada ao local onde vivem, à cultura, à religião e à filosofia de vida ${ }^{25}$. Para Scott-Findlay e Chalmers ${ }^{26}$, é o espaço indispensável para garantir a sobrevivência e a proteção integral dos filhos e demais membros. É a família que proporciona os aportes afetivos, desempenhando um papel decisivo na educação formal e informal, nos valores éticos e humanitários.

Nos períodos de saúde, a família apresenta uma estrutura peculiar, proporciona meios para o crescimento, desenvolvimento, saúde e bem-estar de seus membros. Quando ocorre o câncer, existe uma necessidade de mudança de conceitos e uma reorganização familiar nos vários aspectos da vida, seja a nível social, orgânico, psicológico, emocional e espiritual ${ }^{16,27,28}$. Para Misko e Bousso ${ }^{17}$, o câncer provoca na família uma abrupta mudança e um desequilíbrio na rotina e dinâmica familiar, o que acarreta uma constante busca em lidar com a problemática e manter uma interação saudável entre os familiares - nesse contexto, cursar uma transformação, experienciando e desenvolvendo sua nova história de vida com o diagnóstico ou hipótese da neoplasia ${ }^{7}$.

Ratificando os achados de Melo et al..$^{20}$, Mistura et al. ${ }^{21}$ argumenta que na ocorrência de mudanças na saúde de um dos integrantes da família, todos os demais são afetados, gerando uma problematização em que todos passam por mudanças. Em síntese, a família afeta a saúde do indivíduo, e a saúde dos indivíduos afeta a família ${ }^{20,21}$.

Menezes et al. ${ }^{29}$, comungando com Borges et al. ${ }^{30}$, colocam que o processo de doença acarreta mudanças e transtornos em toda a estrutura familiar. Compartilhando com essa ideia, Araújo et al. ${ }^{31}$, considerando as características das doenças crônicas, ressalta que sua ocorrência altera o contexto familiar, visto que expóe todos os membros a uma maior vulnerabilidade com relação às perdas, dentre elas as de saúde, bem-estar, financeira, equilíbrio físico, mental e emocional.

A literatura pontua que a família se responsabiliza pelo apoio de seus membros quando acometidos por doenças, situação em que o sofrimento acaba se estendendo a todos ${ }^{7,20,24,25,28}$.

A integralidade do sistema familiar é ameaçada, pois cada membro é pessoalmente afetado pelo diagnóstico e pelas suas consequências, principalmente quando o impacto do câncer remete à morte. Prevalece o conceito de que o câncer é uma doença incurável, o que desestrutura todo o sistema familiar ${ }^{8}$.

Estudos como o de Yeh et al..$^{32}$ e Meleski ${ }^{33}$ apontam que, diante da doença, as famílias passam por limitações, enfrentam angústias e reorganizam-se para enfrentar as situaçóes e implicaçóes decorrentes da patologia.

Os relatos apontam que as doenças crônicas possuem algumas características particulares, como longo período de duração, riscos de complicaçóes, rigoroso controle de cuidados permanentes, sequelas e incapacidades funcionais significativas. Características estas que fazem destacar o papel da família frente à responsabilidade por exercer o cuidado a seu membro ${ }^{34,35}$.

Nesse diapasão, Molina ${ }^{7}$ diz que o apoio recebido após a confirmaçáo do agravo representa segurança e força para enfrentar o tratamento, e a família assume o papel de cuidador informal imediato diante das doenças graves, vivenciando situaçóes de desgaste físico e emocional, provocados pelas atividades exaustivas dispensadas à pessoa agravada, como também compartilha com mais proximidade as dores e as angústias do paciente ${ }^{13}$. Para Fisher ${ }^{36}$, a família da pessoa com câncer é concebida como responsável pelo apoio, crescimento e fortalecimento do seu membro. A proximidade junto ao doente provoca ânimo, o que soma muito ao tratamento ${ }^{14}$. Os familiares podem ser considerados pacientes de segundo escaláo, e a ideologia entre eles - de o câncer ser uma patologia incurável - precisa ser desmistificada ${ }^{8}$.

Para Costa Junior et $\mathrm{al}^{37}$, desde o momento do diagnóstico dessa patologia, toda a família pode passar por diversas fases, sendo necessário o acompanhamento sistemático para auxiliar a enfrentarem as ansiedades vivenciadas nas situaçóes que permeiam o processo de tratamento oncológico. 
Mesmo sendo essencial que a abordagem e o enfrentamento do câncer feito pela família reforcem expectativas de esperança ao doente, através de manifestaçóes de sentimentos e atitudes otimistas ${ }^{30,31,34}$, Northouse et al. ${ }^{18}$ ressaltam que esses efeitos não sáo mantidos ao longo do tempo.

Já no pensamento de Motta e Enumo ${ }^{38}$, a instituição em questáo ocupa uma posição central nesse contexto, reduzindo os padróes culturais como também promovendo estratégias particulares, visando sempre promover os cuidados da forma mais eficiente possível.

A parentela tem um papel fundamental no desenvolvimento da convicção do paciente de que o tratamento é eficaz, se transformando em um aliado forte e poderoso, uma vez que seu incentivo faz com que o agravado confie na competência da equipe de saúde e no tratamento proposto ${ }^{22}$. É interessante que se vivencie novas experiências no cotidiano dos familiares e não haja mudanças sociais, alterações nas tarefas diárias, filosofia de vida ou nos relacionamentos intra ou extra familiares, sempre objetivando levar uma vida o mais próximo possível do que se vivia antes da confirmação da doença ${ }^{23}$. Porém, por vez, os parentes frente $\grave{a}$ situaçáo de adoecimento sentem-se impotentes para satisfazer as necessidades relacionadas aos cuidados de saúde e de sustentação do cotidiano familiar. Por isso faz-se necessário capacitá-los para enfrentar a situação ${ }^{26,33}$.

Como sendo os mais atingidos após a descoberta da doença, os parentes passam incondicionalmente por um processo dinâmico, modificando suas formas de enfrentamento e estratégias relacionadas aos eventos clínicos, diagnóstico, efeitos colaterais, recaídas ou morte, percebendo-se comportamentos diversificados relacionados ao enfrentamento do tratamento, a integridade da família, o apoio, o bem-estar emocional e espiritual ${ }^{32,36,37}$.

Motta e Enumo ${ }^{38}$ apontam nesse contexto que se deve utilizar de diversas estratégias de enfrentamento para minimizar o impacto psicológico do câncer, seja em relação ao acometido ou aos que o cercam. Para isso ocorrer, também é necessária a contribuição dos profissionais envolvidos, promovendo uma visão holística e multidisciplinar, buscando compreender nas suas múltiplas relaçóes uma abordagem profissional humanizada profundamente solidária, possibilitando desvelar caminhos além do conhecimento técnico-científico, pois o cuidar implica também empatia, escuta, paciência e zelo ${ }^{39-41}$.

Gutiérrez et $\mathrm{al}^{42}$, comungando com Bergamasco e Angelo $^{41}$, ao tratar sobre esse assunto, enfatizam também o prognóstico, pois as mudanças em saúde determinam açôes que lhes trarão benefícios ou malefícios, fazendo necessário uma melhor atenção pós-operatória, sempre reforçando as orientaçóes para incrementar a adesão aos programas de reabilitaçáo ${ }^{43}$.
Contudo, mesmo existindo a falta de forças e barreiras produzidas pelo trauma de um câncer, o suporte dos familiares ainda se configura como sendo um dos incentivos mais referidos pelas pessoas acometidas para transpor os obstáculos ${ }^{43,44}$.

Faz-se necessário, ainda mais, que esse nicho realize estudos epidemiológicos que incluam vigilância, observação, pesquisa analítica e experimental, análise por tempo, local e características dos indivíduos e principalmente condiçôes relacionadas à saúde, como doenças, hábitos de vida e equipamentos avaliativos adequados. Afinal, a coerência e precisão desses dados são necessários para assistir de uma forma integral quem tem ou passa pelas experiências apresentada neste trabalho.

\section{Considerações finais}

Mediante tudo o que foi desenvolvido neste trabalho, podemos concluir que o apoio dado pela família é extremamente importante e que suas perspectivas podem ser refletidas aos doentes.

O diagnóstico pode ser devastador não só para o diagnosticado, mas também para toda a família. O sentimento de ansiedade frente ao tratamento, irritação e opressão são constantes entre todos. Contudo, a família tem um papel fundamental no desenvolvimento da convicção do paciente: de que o tratamento é eficaz, podendo se transformar num aliado forte e poderoso nesse contexto, mesmo sofrendo agravos em sua estrutura.

O relacionamento intrafamiliar pode até mudar após o diagnóstico, porém, após o susto, devem se tornar mais significativos e melhorar para todos.

Por fim, o intuito deste manuscrito não é finalizar esse assunto, mas sim levantar novas discussóes sobre um assunto extremamente importante para a comunidade da saúde em geral.

\section{Referências}

1. Carvalho MMMJ. Introdução à psiconcologia. Campinas: Livro Pleno; 2003.

2. Regis MFS, Simóes SMF. Diagnóstico de câncer de mama: sentimentos, comportamentos e expectativas de mulheres. Rev Eletrônica Enferm. 2005;7(1):81-6.

3. Trindade ES, Azumbuja LEO, Andrade JP, Garrafa V. O médico frente ao diagnóstico e prognóstico do câncer avançado. Rev Assoc Med Bras. 2007;53(1):68-74.

4. Souza MT, Silva MD, Carvalho R. Revisão integrativa: o que é e como fazer. Rev Einstein. 2010;8(1):102-6.

5. Guimarães DT. Dicionário de termos médicos e de enfermagem. 1a ed. São Paulo: Rideel; 2002. 
6. Sales CA, Matos PCB, Mendonça DPR, Marcon SS. Cuidar de um familiar com câncer: o impacto no cotidiano de vida do cuidador. Rev Eletr Enf. 2010;12(4):616-21.

7. 7. Di Primio AO, Schwartz E, Bielemann VLM, Burille A, Zillmer JGV, Feijó AM. Rede social e vínculos apoiadores das famílias de crianças com câncer. Texto \& Contexto Enferm. 2010;19(2):334-42.

8. SantAnna DB. A mulher e o câncer na história. In: Gimenes MGG, Fávero MH. A mulher e o câncer. Campinas: Livro Pleno; p. 21, 2000.

9. Molina MAS, Marconi SS. Mudanças nos relacionamentos com os amigos, cônjuge e família após o diagnóstico de câncer na mulher. Rev Bras Enferm. 2006;59(4):514-20.

10. Salci MA, Marcon SS. A convivência com o fantasma do câncer. Rev Gaúcha Enferm. 2010;31(1):18-25.

11. Tavares JSC, Trad LAB. Metáforas e significados do câncer de mama na perspectiva de cinco famílias afetadas. Cad Saúde Pública. 2005;21(2):426-35.

12. Malzyner A, Caponero R, Donato EMOD. A metamorfose de uma angústia: o tratamento do câncer da mama de Halsted ao BRCA - 1. In: Gimenes MGG, Fávero M H. A mulher e o câncer. Campinas: Livro Pleno; p. 352000.

13. Adam V, Kitzmann R, Rios M, Pegliasco C, Olivier JB, Raft J. Evaluation of a support group for children of parents with cancer after 4 years of experience. Bull Cancer. 2013;100(3):237-45.

14. Ho SS, So WK, Leung DY, Lai ET, Chan CW. Anxiety, depression and quality of life in Chinese women with breastcancer during and after treatment: a comparative evaluation. Eur J Oncol Nurs. 2013;17(6):877-82.

15. Semedo DSRC. Descrição e compreensão das vivências de familiares de pessoas com doença oncológica e na identificação das dimensôes do processo de resiliência, no contexto da realidade Cabo Verdiana [Dissertaçáo]. Coimbra: Universidade de Coimbra, 2011 [citado em 2016 nov. 9]. Disponível em: https://estudogeral.sib.uc.pt/bitstream/10316/18420/1/ Mestrado\%20Sa\%C3\%BAde\%20P\%C3\%BAblica \%20 -\%20Deisa\%20Salyse\%20Cabral\%20\%20Semedo.pdf. Acesso em: 20 de Dezembro de 2013.

16. Salci MA, Marcon SS. Enfrentamento do câncer em família. Texto \& Contexto Enferm. 2011;20(especial):178-86.

17. Misko MD, Bousso RS. Manejando o câncer e suas intercorrências: a família decidindo pela busca ao atendimento de emergências para o filho. Rev Lat Am Enferm. 2007;15(1):48-54.

18. Northouse L, Kershaw T, Mood D, Schafenacker A. Effects of a family intervention on the quality of life of women with recurrent breast cancer and their family caregivers. PsychoOncol. 2005;14(6):478-91.

19. Helman CG. Cultura, saúde e doença. Porto Alegre: Artmed; 2003.

20. Melo MCB, Barros EM, Campello MCVA, Ferreira LQL, Rocha LLC, Silva IMG, et al. O funcionamento familiar do paciente com câncer. Psicol Rev. 2012;18(1):78-89.
21. Mistura C, Schenkel FW, Rosa BVC, Girardon-Perlini NMO. The experience of accompanying a family member hospitalized for cancer. Fundam Care. 2014;6(1):47-61.

22. Wennman-Larsen A, Tieshelman C. Advanced home care for cancer patients at the end of life: a qualitative study of hopes and expectations of family caregivers. Scand J Caring Sci. 2002;16(3):240-7.

23. Patterson JM, Kristen EH, James GG. The impact of childhood cancer on the family: a qualitative analysis of strains, resources, and coping behaviors. Psycho-Oncol. 2004;13(6) (2004):390-407.

24. Sanchez KOL, Ferreira NMLA, Dupas G, Costa DB. Apoio social à família do paciente com câncer: identificando caminhos e direçóes. Rev Bras Enferm. 2010;63(2):290-9.

25. Azevedo GR, Santos VLCG. (Handicapped) caregiver: the social representations of family members about the caregiving process. Rev Lat Am Enferm. 2006;14(5):770-80.

26. Scott-Findlay S, Chalmers K. Rural families perspectives on having a child with cancer. J Pediatr Oncol Nurs. 2001;18(5):205-16.

27. Salci MA, Marcon SS. As mudanças no cotidiano familiar e na vida da mulher após o início do tratamento para o câncer. REME Rev Min Enferm. 2010;14(1):43-51.

28. Bielemann VLM. A família cuidando do ser humano com câncer e sentido a experiência. Rev Bras Enferm. 2003;56(2):133-7.

29. Menezes CNB, Passareli PM, Drude FS, Santos MA, Valle ERM. Câncer infantil: organização familiar e doença. Rev Mal-Estar Subj. 2007;7(1):191-210.

30. Borges ADVS, Silva EF, Toniollo PB, Mazer SM, Valle ERM, Santos MA. Percepção da morte pelo paciente oncológico ao longo do desenvolvimento. Psicol Estud. 2006;11(2):361-9.

31. Kovács MJ. Bioética nas questôes da vida e da morte. Psicol USP. 2003;2(14);115-67.

32. Yeh CH, Lee TT, Chen ML. Adaptational process of parents of pediatric oncology patients. Pediatr Hematol Oncol. 2000;17(2):119-31.

33. Meleski DD. Families with chronically ill children: a literature review examines approaches to helping them cope. Am J Nurs. 2002;102(5):47-54.

34. Araújo LZS, Araújo CZS, Souto AKB, Oliveira MS. Cuidador principal de paciente oncológico fora de possibilidade de cura, repercussóes deste encargo. Rev Bras Enferm. 2009;62(1):32-7.

35. 35. Nascimento LC, Rocha SMM, Hayes VH, Lima RAG. Crianças com câncer e suas famílias. Rev Esc Enferm USP. 2005;39(4):469-74.

36. Fisher HR. The needs on parents with chronically sick children: a literature review. J Adv Nurs. 2001;36(4):600-7.

37. Costa Junior AL, Coutinho SMG, Kanitz S. O enfrentamento do câncer em crianças: a intervenção da psicologia. Pediatr Mod. 2000;36(5):330-3. 
38. Motta AB, Enumo SRF. Intervenção psicológica lúdica para o enfrentamento da hospitalização em crianças com câncer. Psic Teor Pesq. 2010;26(3):445-54.

39. Costa CA, Filho WDL, Soares NV. Assistência humanizada ao cliente oncológico: reflexóes junto à equipe. Rev Bras Enferm. 2003;56(3):310-4.

40. Carvalho MVB, Merighi MAB. O cuidar no processo de morrer na percepção de mulheres com câncer: uma atitude fenomenológica. Rev Lat Am Enferm. 2005;13(6):951-9.

41. Bergamasco RB, Angelo M. O sofrimento de descobrir-se com câncer de mama: como o diagnóstico é experienciado pela mulher. Rev Bras Cancerol. 2001;47(3):277-82.
42. Gutiérrez MGR, Bravo MM, Chanes DC, Vivo MCR, Souza GO. Adesão de mulheres mastectomizadas ao início precoce de um programa de reabilitação. Acta Paul Enferm. 2007;20(3):249-54.

43. Prado MAS, Mamede MV, Almeida AM, Clapis MJ. A prática de atividade física em mulheres submetidas à cirurgia por câncer de mama: percepçáo de barreiras e benefícios. Rev Lat Am Enferm. 2004;12(3):494-502.

44. Erickson VS, Pearson ML, Ganz PA, Adams J, Kahn KL. Arm edema in breast cancer patients. J Natl Cancer Inst. 2001;2(93):96-111. 